\title{
Integrating the Elder into the Labor Force: Consequences and Experience for Insurance
}

\author{
by F. Peter Libassi*
}

The transition to retirement by growing elderly populations and protecting their economic security are critically important problems not only throughout Europe but worldwide, in North America and in Japan as well. Ultimately, developing nations where current high birth rates obscure the absolute increase in the elderly dependents will also face these issues.

\section{An approach to the issue}

There are at least two quite distinct ways of approaching the issue of continued employment of older workers as a supplement to social insurance, private pensions and private savings.

The first, spelled out in several papers of "The Fourth Pillar" research programm**, begins with large questions of social policy: the strain of financing social insurance programs, the demographic trends and persistent unemployment.

The second bears on the same questions, but indirectly. It begins from an immediate problem near at hand: how can an employer harness the potential of older workers and retirees to meet current demand for labor and skills?

This paper uses the second point of departure, perhaps reflecting its American focus on the immediate. This perspective reflects the pressing nature of America's "retirement problem": an emerging shortage of labor while too many people are opting to retire too soon.

In this respect, the American experience may not be directly applicable to other countries. Nonetheless, focusing on near-term, practical challenges may be a useful way of engaging interest in the longer-range, ultimate question of how to meet modern societies' social security, insurance and savings needs.

\footnotetext{
${ }^{*}$ Senior Vice President, Corporate Communications, The Travelers Insurance Companies, Harford Conn., USA.

** See "The Four Pillars" Newsletter published by the Geneva Association
} 


\section{The policy setting}

There are important characteristics of American demographics, economic conditions and public policy which may differ from those of other countries. It is important to bear each of these in mind to put the following remarks in context.

The first characteristics or trend is grounded in demographics. America's postwar "baby boom" was much larger and longer-lasting than the European experience. From 1945 to 1964 , in 19 years, the U.S. added 76 million children, about one-third of our total current population. Dealing with their entry into the labor market, and with the concurrent wholesale migration of women into the American workforce, was a major economic challenge.[1]

Now, however, the U.S. is on the other side of the baby bulge. The pipeline is running dry: from 1979 to 1990 , the number of new people entering the American workforce will decline by almost half. Over the past decade the baby boomers and women looking for jobs have offset the continuing fifty-year decline in labor force participation by middle-aged and older men. Now, however, we are entering uncharted new waters. [2]

That is of particular relevance because of a second American characteristic, concerning job creation. For whatever reason the United States has been very good at expanding employment. Over the last decade, the U.S. economy has created more than 18 million new jobs. [3] While European unemployment is hovering around 10 percent, the U.S. rate is dipping toward 5 percent.

Consider the intersection of these two trends: a sudden, sharp decline in the availability of new workers - women and young people - and a sustained growth in new jobs. Clearly, the American economy is becoming labor-short.

Consider the pronounced inclination of middle-aged and older workers to retire as early as possible, America has a "retirement problem" right now. In various sectors of the economy and various regions of the country, American businesses are urgently trying to find new ways to attract and retain sufficient numbers of qualified employees.

For the U.S., a discussion of the "Fourth Pillar" - expanded employment of older workers - is framed by these two trends of declining new entrants into the workforce and continued generation of new jobs.

Of course, the preference for early retirement and the declining availability of younger workers translate into a longer-term retirement problem, as well: too few active workers supporting too many retiree beneficiaries of social insurance programs. So while the focus on the near-term implications of the "Fourth Pillar" is part of the solution, it does not wholly resolve the major structural challenges of retirement financing facing the American economy.

Finally, it is vital to remember that beyond the demographic and economic differences, in certain respects America operates differently, in its social programs. Compared to many European countries, the U.S. is more likely to combine private and public elements in devising ways to provide human or social services. Furthermore, we are incrementalists, addressing the issues a piece at a time. We avoid talking comprehensively about the means and needs of people. In the case of current and future retirees, here we nudge up the payroll tax rate a bit; there we extend the Social Security retirement age by two years over the next several decades. 
This gives rise to a curious spectacle, such as the debate in Congress and Presidential campaigning this year over whether to tax the elderly for their own supplemental "catastrophic" health insurance, and - as a separate issue - whether to create public programs for long-term home-based or nursing home care for the elderly.

In most instances these problems are resolved, or papered over, by enacting programs and then devising exclusionary eligibility or funding formulas to hold the cost down to some level that appears tolerable in the current budget.

\section{An American perspective on the "Fourth Pillar"}

So in offering an American perspective on the "Fourth Pillar," this paper proceeds from the specific and immediate to the general, rather than the other way around.

This approach represents fairly the way Americans are addressing the issue. For example, at the 1981 White House Conference on Aging, much was made of a paper on «Economic Policy In An Aging Society." It boldly projected that increased elderly employment opportunities could, using conservative assumptions, increase the Gross National Product by 4 percent and boost government revenues by $\$ 40$ billion over the next 25 years, in current dollars. ${ }^{[4]}$ What follow-up has there been to this comprehensive, macroeconomic work? Essentially none.

By the same token, with the sustained growth in our employment this decade, theoretical discussion of the role of job-sharing as a means to reduce unemployment has faded in importance.

\section{Experience at The Travelers}

The Travelers has been dealing with these issues - first casually, and more recently in an organized way - for about 15 years, both as employer and as insurer with significant exposure to the health care and private pension businesses. While our experience of late has been carefully planned and documented, there is no reason to suspect other companies could not conduct similar programs. In fact, a lot of what we do appears to have broad applicability.

The company's initiation into the mysteries and opportunities of post-retirement employment dates to the early 1970s. At that time, the Office of Consumer Information, which handles customer inquiries and complaints, was staffed by volunteers.

Someone perceived that retirees, who carried vast knowledge of our products and organization out the door with them when they left, were well trained for this kind of work. Better still, they were temperamentally suited to customer relations. Since they wanted to do the job - despite constraints imposed by our pension policy - retirees were hired to staff our telephone bank for customer queries.

That experiment proved to be a significant success. Today, 16 retirees, working parttime, handle about 60,000 inquiries per year. Since a customer is attached to each of those calls, the work of our formerly retired employees in Consumer Information is of real worth to the company's reputation. 
In 1980 , we set out to determine whether this beachhead could be enlarged. We mailed a "Pre-Retirement Opinion Survey" to all Travelers employees over the age of 55 to ascertain their interest in post-retirement employment. [5]

Our first surprise was in the rate of return of the questionnaire. Despite the fact that the questionnaire was distributed by mail with no follow-up, 79 percent of the older workers returned the form, indicating that it addressed a deep interest among recipients.

The substantive results were even stronger: 85 percent of the respondents expressed interest in some form of paid employment after they retired, with over one-half saying they preferred part-time work at The Travelers.

At that time, the company was already using outside agencies to recruit temporary and part-time workers to help cover vacations and illnesses, and to staff special projects. Our home office operations in Hartford employ about 10,000 people, a very significant presence in a metropolitan area of modest size. And of course we compete with other large employers with similar workforce needs - notably insurers and banks.

So we decided to create our own internal employment agency to recruit, hire and, as necessary, train our own retirees to fill our temporary employment needs. With that, we launched the Retiree Job Bank. To get things off on the right footing, we hired two retirees - both in their 70's - to establish, organize and run the program. As they fleshed out the plan, it was designed to offer flexible, part-time and temporary assignments to a registered list of qualified workers. Setting up this program required that the company address larger policy questions, which were resolved in 1980 by eliminating mandatory retirement and changing our pension policy to permit retirees to work 960 hours annually - essentially halftime - without jeopardizing pension and health benefits.

At first, Travelers' supervisors were skeptical about the productivity of older workers. But with a little experience, these supervisors became converts and are now strong advocates of hiring retirees.

From 1981 through 1985, the Job Bank registered 300 Travelers reetires, and grew itself into a problem: insufficient supply. The performance of Job Bank people was rated far above those supplied by temporary employment agencies. These comments come from supervisors' written evaluations:

- Excellent worker - would like to reemploy in near future;

- Very pleasant - assumed quickly and efficiently, excellent attitude, reliable, good skills;

- Handled her assignment in a professional and expeditious manner with minimal guidance; and, simply,

- A real work horse.

To meet demand, Job Bank registration was extended to retirees from other companies. In 1985, turning the traditional retirement party on its head, we threw our first "UnRetirement Party" to expand Job Bank enrollmemts. As a result we signed up excellent, skilled retirees from Aetna Life and Casualty, Connecticut General and The Hartford Insurance Group - all to work for The Travelers. 
Today, we have 750 Job Bank participants, about half from The Travelers and half from other companies. In any given week 250 of these participants will be working at The Travelers. In the aggregate, they fill half or more of our overall need for temporary workers.

Although we pay them better wages than they could receive from agencies - the midpoint of our salary range for the assignments they fill - Travelers saves more than one million dollars annually by avoiding employment agency fees. That measurement of course excludes very valuable intangibles, such as the greater reliability, responsibility and productivity of Job Bank workers compared to temporaries hired through employment agencies.

Even with sustained recruiting, demand outstrips supply for Job Bank people. So Travelers has taken to training those available to enhance their skills.

This has lead to a very interesting discovery, further challenging unfounded assumptions about the elderly. In a company like Travelers, familiarity and comfort with computers is becoming mandatory. There is a terminal or workstation on essentially every desk.

Our decision to offer computer training to retirees contradicted two assumptions which are widespread among employers: that older people are unwilling to learn how to use new technologies, or that they are incapable of doing so.

Our experience has proven those assumptions wrong. In a survey, 65 percent of the Job Bank retirees with typing skills expressed interest in further training. Further, when devising computer training programs to meet that interest we assumed that retirees would prefer their own classes. So we established segregated courses to provide a learning environment that encouraged camaraderie and minimized the pressure to keep pace with younger people. But, we soon found those special classes to be unnecessary, and retirees were enrolled in - and successfully completed - the training programs offered to all Travelers people.

The return on our training investment has been substantial. Far from being wasteful the common attitude toward spending money to train older workers - this program has yielded a productive group of people not otherwise available to us at any cost.

Obviously, Job Bank employees are temporary workers. Travelers offers them no extra health-care or pension benefits beyond that they may already be receiving. Nor does the company or the temporary employee make contributions toward such programs for their Job Bank work. The company does, of course, withhold income taxes and Social Security payroll taxes from Job Bank workers' checks, so to this extent their continued employment produces more revenue for the First Pillar.

The Travelers experience in changing workers' disposition to retire has been more modest. While the company abolished mandatory retirement eight years ago, we currently have just 199 full-time employees over age 65, out of a nationwide workforce totaling 34,000 .

Like their younger colleagues, these employees make contributions toward health insurance benefits, and continue to build credits toward the private pension program, which The Travelers funds without employee contributions. Thus, their decision to continue working substantially augments not only their immediate incomes, but also their expected private pension benefits. 


\section{Retirement and work: survey findings}

Since the 1980 preretirement survey, Travelers has conducted two other in-house surveys designed to asses scientifically the attitudes and experiences of retirees. Both surveys aimed at comparing people who retired and chose to come back through the Job Bank with those who retired and stayed home.[6]

One caveat about interpreting the results: the samples were not random. The 1982 survey included all Travelers retirees who where working part-time for the company, plus 20 percent of remaining retirees who were under 75 years old. The most recent survey, administered earlier this year and just now being analyzed, consisted of former Travelers employees who retired within the past ten years, plus all of the people registered with the Job Bank. As noted, among the Job Bank registrants about half are former Travelers employees while half previously worked elsewhere.

The 1982 survey revealed that 62 percent of retirees expressed a strong desire to continue some form of employment. This did not reflect unhappiness about their retirement, as 87 percent of retirees said they enjoyed being retired. They wished to have the best of both worlds: continued employment while they enjoyed their retirement.

While financial needs of course entered into their decisions, the retirees expressed even stronger reasons for wanting to continue working. Among the needs they identified were:

- a sense of accomplishment and worth from working;

- the opportunity to be with people; and

- something to do with their time.

Their self-reported job satisfaction was high, with more than 90 percent of retirees enjoying their work, schedule and workplace colleagues.

The 1988 survey reveals that the decision to resume working, as indicated by registering with the Job Bank, is most heavily influenced by income. But the data also reveal interesting social traits of those who re-entered the workforce.

As a general observation, those who chose "partial retirement" - that is, some form of work after their formal retirement - seem to have more limited financial resources and greater doubts about the wisdom of their decision to retire than those who stopped working outright. The survey included in financial resources wages, investment income, pensions and benefits such as health insurance and Social Security benefits.

Those who resumed working also reported that their social activities - their ability to keep busy and to interact with other people - depended far more heavily on the workplace than did those of retirees who chose not to work again.

Demographic differences exist, too. Post-retirement workers tend to be younger than nonworking retirees, as might be expected. Also, their health is somewhat better.

These findings suggest that efforts aimed at attracting retirees at least part of the way back into the workforce will be more appealing if they include jobs suitable for people with greater needs for current income and for whom work is an important part of social life. 
For such workers, outreach programs such as the Job Bank show up in the survey as particularly effective channels to the kind of assignments retirees want and are skilled to perform. While the sample biases this result to an unknown degree, it is significant that these programs still show up as far more important in producing jobs than the next leading avenue, referrals from friends.

Finally, the survey raises an unaddressed issue in retirement policy: caregiving responsibilities. Nine percent of the nonworking women contacted in the survey cited their need to provide elder care as the reason for their decision to retire when they did.

\section{Discussion}

It is clear that for participants in the Job Bank, we have created a new social environment at The Travelers. By changing our pension policy and employment practices, we have brought about a new mindset among both retirees and our supervisors.

Certainly our retirees now know that continued work on a part-time or temporary basis beyond retirement is an acceptable, workable option. They know that they are needed, that the importance of their work is recognized, and that they are valued for their contribution. The participants report that they like the extra income and, perhaps of equal importance, they appreciate the social benefits of feeling wanted and being in the company of other people. A 79-year-old Office of Consumer Information employee says, "Being with people of all ages keeps me feeling young."

At the same time, our supervisors recognize that they have access to a skilled, productive, professional labor resource and from The Travelers' perspective, the program makes hard economic sense. The dollar savings, productivity gains and reputational benefits from the Job Bank are significant.

In The Travelers' local community, where under 3 percent of those who seek jobs are without them, essentially all those who have minimal language and office skills are employed. The labor market is effectively at or beyond full employment already, and must expand the available workforce, by attracting retirees or training unskilled. In this environment, the retiree program is a real competitive advantage.

The Job Bank experience is also consistent with other research findings. For example, survey research conducted for the National Council on the Aging indicates that older Americans generally have a strong interest in part-time work. ${ }^{[7]}$ This conforms to our in-house surveys. The Job Bank is designed to provide just this sort of opportunity, and the response to it validates the importance of offering flexible, unconventional terms of work to accommodate the otherwise retired.

At the same time, retirees apparently work less than they indicate they would like to, and they report little in the way of actively hunting for jobs. ${ }^{[8]}$ Hence the importance of reaching out to these potential workers, as Travelers has through "Un-Retirement" job fairs, publicity, and advertising. In total, these amount to very modest recruiting expenditures, particularly relative to the number and quality of prospects they have brought to the company.

The point, while relatively simple, is easily overlooked. When appealing to a new segment of the potential workforce, with different work interests and constraints, employers need to be accommodating in devising schedules, designing jobs, and then in communicating what they offer. 
Internally, this is easy to accomplish by briefing employees before they retire so they are acquainted with opportunities. When companies look beyond their own retirees, more creative tactics are called for. But surely they are well within the talents of personnel professionals who are constantly recruiting among outsiders.

Beyond these immediate economic benefits and the practical details of attracting and using retired workers, companies may find additional business regards from their relationships with older workers.

Building on the Job Bank, The Travelers has created a comprehensive Older Americans Program over the past half decade, with broad policy implications for American society and with genuine relevance to the company's business. Elements of the program involve not just the employment initiatives, but also health promotion, long-term care insurance, and support for research and training in gerontology and geriatics.

A primary goal of the program is to increase the economic security of older people through extended employment. The benefits in terms of self-sufficiency and reduced reliance on public social insurance programs are obvious. They also correspond to the social policy aspects of Travelers' self-interests as insurers in the business of selling health and pension services to corporate clients on behalf of their employees, near-retirees, and retirees. Serving such beneficiaries constitutes one of the principal private insurance markets in the United States.

There are important connections among elements of the Older Americans Program which bear on the viability of the Fourth Pillar and on efforts to reverse the trend toward early retirement. For example, many current middle-aged employees face increasingly severe burdens of caring for their dependent parents and relatives. This is not a trivial factor: among Travelers home office employees over 30 years of age, 28 percent reported in a 1985 survey that they were providing such care, and that the average time devoted each week to such responsibilities exceeded 10 hours. [9]

The U.S. Senate Special Committee on Aging analyzed the same problem another way. In 1982, according to its research, 2.2 million people who averaged 57 years old provided unpaid care to disabled elderly people outside institutions. Of these caregivers, about half held jobs, and significantly, 9 percent had quit working to provide care. Four-fifths gave care seven days a week, for an average of four hours daily.[10]

This suggests very strongly that elder care responsibilities are a real contributing factor in the decisions of people in their late 50's and early 60's to retire early. Thus, insurers' ability to devise long-term care protection, along or in conjunction with public programs, may pay large, unforeseen dividends in boosting employee productivity and reducing mounting pressures for premature retirement.

\section{Conclusions}

What conclusions can be drawn and what problems remain unresolved from The Travelers' employment experience and surveys?

At the most basic level, older workers can perform the kinds of work the company requires. They do so comfortably and efficiently alongside our full-time younger workers. They are responsive to part-time opportunities. And they are eager, good learners when offered training. 
Given these characteristics, it is promising that opportunities for part-time work appear to be increasing in the American economy. Most current estimates put the number of part-time jobs at about 20 million, roughly one-fifth of all jobs - a substantially higher proportion than in the EC. ${ }^{[1]}$ Although most of these are for low-skilled service work, such as retail or restaurant positions, there is anecdotal evidence that companies are maintaining leaner staff and coping with the demand by resorting to the use of more highly skilled and professional part-time workers.

Ironically, one consequence of the frenzied corporate takeovers and restructurings in the American economy is a surge in less than full-time jobs. The appeal to the employer is that most such positions do not include health and pension benefits - so they contribute little to lessening the ultimate strains on retirement financing.

Given the need for labor and given a little imagination, there are numerous opportunities for use of retirees throughout the economy. These are just a few examples outside the insurance industry. [12]

Technical and managerial: Corning Glass Works invites workers with engineering, accounting and other skills to return to work part-time. With flexible scheduling, counseling and phased retirement programs for salaried employees, the company has managed to attract several hundred participants.

Carpenters and builders: Georgia Power Company has contracted outside to employ 65-plus adults to weatherize the homes of older customers. Since 1982, 160 workers have caulked and weatherstripped 30,000 homes to reduce energy consumption.

Non-office services: McDonald's Corporation's McMasters program recruits older workers for fast food restaurant jobs in tight labor markets nationwide.

Professional: Polaroid Corporation's Project Bridge will certify retiring employees with mathematics or science backgrounds for second careers as teachers.

As these diverse initiatives suggest, the willingness to consider using older workers is spreading, driven by the sharp prods of scarce labor and skills.

While such part-time work fills the needs of employers and increases retirees' income, it should over time also lessen the demands for expanded public programs. Nevertheless, it is not the sole solution to the problems of financing public retirement programs.

On the one hand, such work surely increases retirees' incomes from private sources, a desirable goal, and contributes resources to public pensions through the payroll tax mechanism.

But on the other hand, the availability of such work may make it easier for full-time employees to retire early, confident that they can secure supplementary income when they want to. This decision, of course, exacerbates the public pension funding problem.

So, the basic problem of encouraging workers to delay their retirement and to extend their full-time employment remains. The solution to this issue extends beyond The Travelers' experience to date.

Indeed, even more than a few years ago, this observation from Malcolm Morrison of George Washington University rings true: 
Nearly everyone is in favor of providing more employment opportunities for older people who want to work. Despite some of the barriers to employment and the contradictions in public and private retirement policies, most of us think that ways can be found to modify corporate policy and practice to permit older people to work... However, it is well known that corporate incentives for early retirement are now ubiquitous and are expanding, whereas incentives to retain or hire older people have received very little attention from management.[13]

That is, companies are still focusing on their other short-term business needs, which increasingly often involve reducing costs by offering early retirement to whole classes of workers.

Nonetheless, I believe that companies like our own can play a major constructive part in building the Fourth Pillar. While social policies can help encourage employers and employees to delay retirement, market forces will play the strongest role in bringing about this needed change in behavior.

To quote Robert Butler, the American gerontologist:

Retirement is primarily a Twentieth Century phenomenon. In the past, the sailor became a sail-maker, the toiler in the fields began to work in the granary. Technology changed the way one worked. It can also be applied to altering the work burden in accordance with the accompaniments of age and various diseases and disabilities.

In this century, fewer jobs require great muscle strength. This change in occupation sets the stage for greater participation of older persons in the workforce. [14]

That is to say, office environments are ideally suited to tapping the potential of older workers. In a setting of labor scarcity, institutions like insurance companies are in a relatively favorable position to use retirees or to encourage their employees to defer retirement. 


\section{REFERENCES}

1. PIFER, Alan, "Our Aging Society: An Overview of the Challenge", America's Aging Workforce: A Travelers Symposium (Proceedings) (hereafter cited as Symposium), 1986, p. 5.

2. SALISBURY, Dallas L., "Aging America: Private-Sector Impact”, Symposium, pp. 20-21.

3. REVZIN, Philip, "As Trade Gap Closes, Partners of U.S. Face End of the Gravy Train", The Wall Street Journal, March 17, 1988, pp. 1, 15.

4. "Economic Policy in an Aging Society: A Study of the Future Impact of Public Policy Changes on the Economy and on the Elderly", Final Report of the Technical Committee on an Age-Integrated Society - Implications for the Economy, 1981 White House Conference on Aging, p. 1.

5. "The Travelers Preretirement Opinion Survey: Reported Results", January 1981.

6. "The Travelers Retirement Opinion Survey", July 1982, and "The Travelers Companies 1988 Retiree Survey", forthcoming.

7. PAUL, Carolyn E. et al., Expanding Part-Time Work Options for Older Americans: A Feasibility Study, Employment and Retirement Division, Ethel Percy Andrus Gerontology Center, University of Southern California, December 1983, p. 1.

8. Salisbury, op. cit., p. 21.

9. "The Travelers Employee Caregiver Survey", June 1985, pp. 1, 7.

10. For a useful summary, see "The Cost of Caring for an Aging Population", National Journal, April 23, 1988, p. 1095

11. "The Problem of Retirement in Industrialized Countries and the Fourth Pillar", Geneva Association Research Programme on Social Security, Insurance and Savings, August 1987, p. 9. U.S. Bureau of Labor Statistics data put the figure at 18\% in March 1988; the Conference Board estimates $25 \%$ of jobs are part-time.

12. ARAVANIS, Sara C., LEVIN, Robert and NIXON, Terry T., editors, Public/Private Partnerships in Aging: A Compendium, National Association of State Units on Aging and Washington Business Group on Health, Washington, D.C., November 1987, pp. 1, 2, 5, 10.

13. MORRISON, Malcolm H., "Corporate Practices: Personnel Programs and Management Strategies for Older Workers", Symposium, p. 58.

14. BUTLER, Robert N., M.D., "Health, Aging and Productivity", Symposium, p. 46 